\title{
LOW TEMPERATURE EFFECTS ON PWR FUEL ASSEMBLY CRITICALITY CALCULATIONS
}

\author{
Matthias Behler, Volker Hannstein, and Fabian Sommer
}

\author{
Gesellschaft für Anlagen- und Reaktorsicherheit (GRS) gGmbH \\ Boltzmannstraße 14, 85748 Garching, Germany
}

Matthias.Behler@grs.de, Volker.Hannstein@grs.de, Fabian.Sommer@grs.de

\begin{abstract}
One of the parameters affecting the neutron multiplication factor $\mathrm{k}_{\text {eff }}$ of a system containing fissile material is the system temperature. Therefore, the effect of temperature on criticality safety analyses is an area of international interest. In this context, the Working Party on Nuclear Criticality Safety (WPNCS) of the OECD Nuclear Energy Agency (NEA) formed a subgroup to define and execute a code-to-code comparison benchmark to investigate the effect of temperature on $\mathrm{k}_{\text {eff }}$ for PWR fuel assemblies. Two configurations of a generic watermoderated PWR fuel assembly were analysed at different temperatures between $233 \mathrm{~K}$ and $588 \mathrm{~K}$, and with different assembly burnups. Based on this benchmark, GRS performed an additional study to investigate the impact of the moderator densities, the neutron reaction cross sections and the thermal scattering data on $\mathrm{k}_{\text {eff }}$ separately.

The benchmark results show the expected decrease of $k_{\text {eff }}$ with temperature and a considerable jump in $\mathrm{k}_{\text {eff }}$ at the phase transition of the moderator. The additional investigation demonstrates that the jump in $k_{\text {eff }}$ is mainly caused by the change of the moderator density due to the phase transition. The change of the thermal scattering data due to the phase transitions leads to a similar but smaller jump in $k_{\text {eff. }}$ Furthermore, the actual impact of the different parameters on $k_{\text {eff }}$ depend strongly on the considered fuel assembly configuration.
\end{abstract}

KEYWORDS: criticality safety, neutron multiplication factor, thermal scattering data, temperature effect

\section{INTRODUCTION}

In criticality safety analyses of fissile material, the most unfavourable configurations need to be analysed considering normal and credible abnormal conditions. Typically, such an analysis is based on the determination of the neutron multiplication factor $k_{\text {eff. }}$ One of the parameters affecting $k_{\text {eff }}$ is the temperature, since the temperature influences material densities and phases, as well as neutron reaction cross sections and thermal scattering data. Hence, an appropriate temperature range needs to be considered. For example, the IAEA Transport Regulation SSR-6 [1] requires the consideration of ambient temperatures from $-40^{\circ} \mathrm{C}$ to $38^{\circ} \mathrm{C}$ (unless the Competent Authority specifies otherwise). Therefore, the effect of temperature on $k_{\text {eff }}$ is an area of international interest. Especially, temperatures below $273 \mathrm{~K}$ are currently under investigation [2]. For instance, thermal scattering data of hydrogen bound in ice was recently included in the newest releases of nuclear data libraries, e.g. ENDF/B-VIII.0 [3] or JEFF-3.3 [4]. 
In this context, the Working Party on Nuclear Criticality Safety (WPNCS) of the OECD Nuclear Energy Agency (NEA) formed a Sub Group to define and execute an code-to-code code comparison benchmark to investigate the effect of temperature on $\mathrm{k}_{\mathrm{eff}}$ for PWR fuel assemblies [5, 6]. In this benchmark attention was payed to temperatures below $273 \mathrm{~K}$ to investigate the impact of the reaction cross sections and of the change in the thermal scattering data of bound hydrogen in this temperature region. Hence, the $\mathrm{k}_{\mathrm{eff}}$ of two configurations of a generic water-moderated PWR fuel assembly were analysed at temperatures between $233 \mathrm{~K}$ and $588 \mathrm{~K}$.

Based on this benchmark, GRS performed an additional study on the effect of the temperature on $\mathrm{k}_{\text {eff }}$ to investigate the temperature-dependent impact of the reaction cross sections, the thermal scattering data and the moderator density on the neutron multiplication factor separately, while the OECD/NEA benchmark analysed only the combined effect. Both, the GRS contribution to this benchmark and the additional investigations are described in this paper.

\section{OECD/NEA BENCHMARK}

\subsection{Benchmark Specifications}

In the OECD/NEA benchmark [5] two configurations of a generic water-moderated PWR fuel assembly were analysed: a single water-reflected fuel assembly (Single Unit) and an infinite array of identical fuel assemblies (Infinite Array). In both cases the same generic 17x17-25 PWR fuel assembly was used, see Fig. 1. In the first case the single fuel assembly was surrounded be a $1 \mathrm{~m}$ water reflector, while in the second case the infinite array of the fuel assemblies was built without any water gap between the fuel assemblies. Both configurations were considered infinite in the axial direction, i.e. two-dimensional models were used. The configurations were analysed at five different temperatures $(233 \mathrm{~K}, 253 \mathrm{~K}, 293 \mathrm{~K}$, $333 \mathrm{~K}$ and $588 \mathrm{~K}$ ) considering three different fuel compositions with an initial enrichment of $4.5 \mathrm{wt}-\%$ of ${ }^{235} \mathrm{U}$ : fresh fuel as well as irradiated fuel with burnups of $30 \mathrm{GWd} / \mathrm{t}$ and $45 \mathrm{GWd} / \mathrm{t}$, respectively. The irradiated fuel compositions were taken from a previous OECD/NEA burnup credit criticality safety benchmark [7].

For each analysed combination, the reaction cross sections, the thermal scattering data and the moderator density were adjusted according to the chosen temperature. The moderator was assumed to be ice instead of water for the temperatures of $233 \mathrm{~K}$ and $253 \mathrm{~K}$. For temperatures up to $333 \mathrm{~K}$ normal pressure was

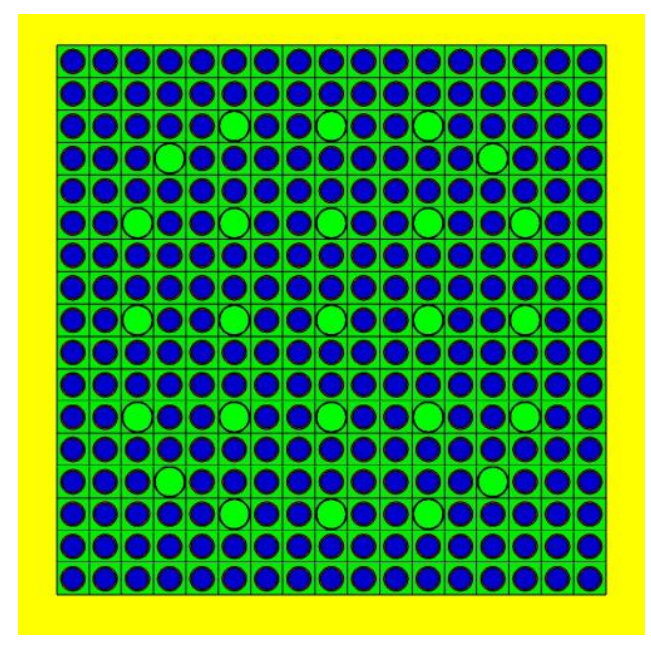

Figure 1. Generic water-moderated 17x17-25 PWR fuel assembly reflected by water. 
assumed, and for $588 \mathrm{~K}$ a typical PWR moderator pressure was applied. In contrast to the moderator, the parameters of the water reflector in the case of the single fuel assembly were kept constant at their values of $293 \mathrm{~K}$. The detailed description of the benchmark can be found in [5].

\subsection{GRS Benchmark Results}

GRS calculated the requested neutron multiplication factors with three different Monte Carlo codes: KENO-V.a of the SCALE package version 6.2.2 [8], OpenMC version 0.9.0 [9] and MCNP version 6.1 [10]. For all three codes, the nuclear data were taken from the latest ENDF/B-VIII.0 library [3, 11], which contains scattering data of hydrogen and oxygen bound in ice. The nuclear data in the so-called ACE format required by MCNP were taken directly from a library made available by the Los Alamos National Laboratory [11]. This library is based on the corresponding ENDF-files provided by the National Nuclear Data Center (NNDC) at Brookhaven National Laboratory (BNL) [3]. This ACE formatted data was also used for OpenMC after converting it to the OpenMC specific HDF-5 format. The ENDF/B-VIII.0 data in the so-called AMPX format required by the SCALE package were generated from the ENDF-files provided by the NNDC using the AMPX code system [12] (included in the SCALE package). Since the ENDF/B-VIII.0 thermal scattering data of hydrogen in water included in this ENDF-files caused an unexpected error during the conversion process, the thermal scattering data of hydrogen in water of the ENDF/B-VII.1 library was used instead to generate the AMPX formatted data.

Hence, the thermal scattering data of hydrogen bound in ice were used for the temperatures of $233 \mathrm{~K}$ and $253 \mathrm{~K}$ to take the moderator phase correctly into account. In the case of MCNP, the required temperaturedependent reaction cross sections were constructed by mixing two sets of nuclides with the respective nearest temperatures given the ENDF/B-VIII.0 library. However, the thermal scattering data were applied without interpolation. For the temperatures of $333 \mathrm{~K}$ and $588 \mathrm{~K}$, for which no scattering data are included in the in ENDF/B-VIII.0 library, the scattering data of the temperatures $324 \mathrm{~K}$ and $600 \mathrm{~K}$ were used instead. This leads to a small error in the calculated $k_{\text {eff }}$ of less than $70 \mathrm{pcm}\left(1 \mathrm{pcm}=10^{-5}\right)$ [13]. In the case of KENO-V.a and OpenMC, their internal methods to adjust the reaction cross sections and scattering data were applied.
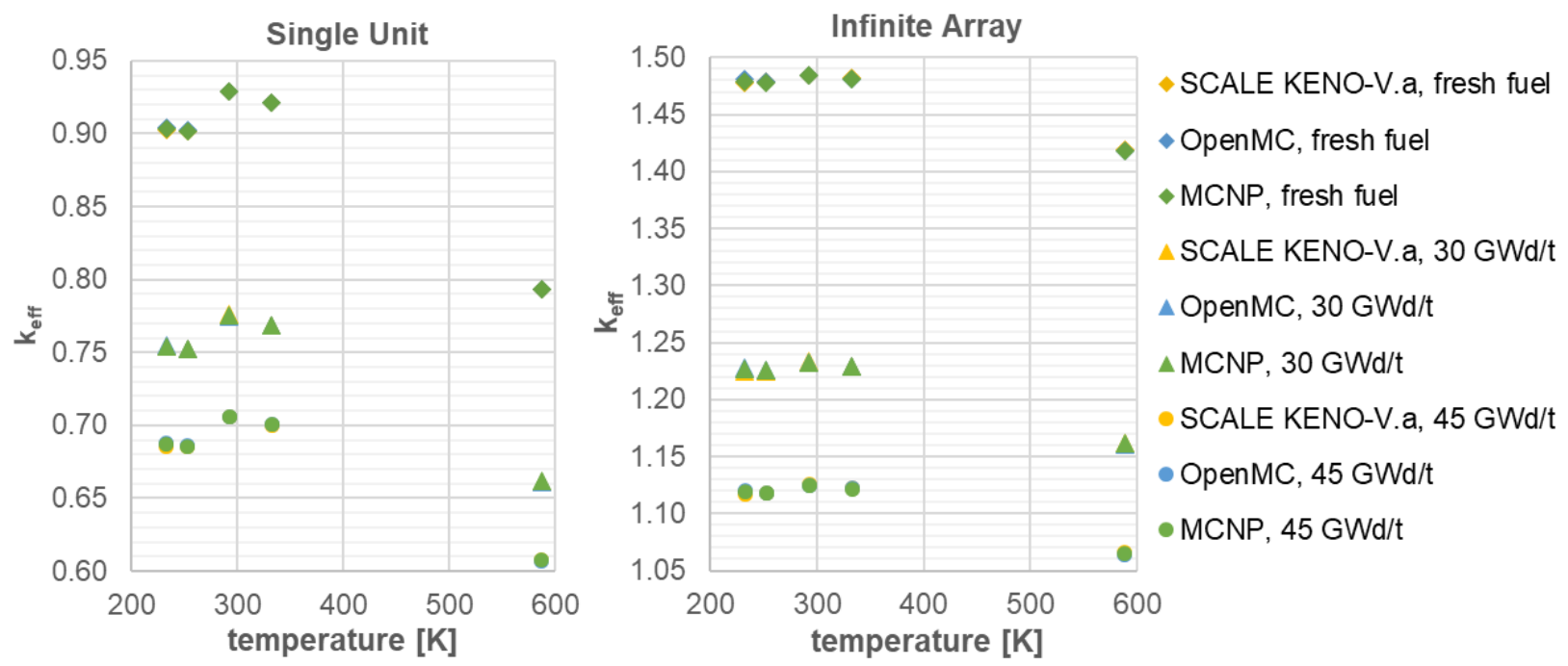

Figure 2. Calculated neutron multiplication factors $k_{\text {eff }}$ of the benchmark cases. 
The calculated neutron multiplication factors $\mathrm{k}_{\text {eff }}$ of the different benchmark cases using the different codes are given in Fig. 2. For the temperatures above and below the phase transition of the moderator, the results show the well-known temperature-dependent behaviour, i.e. $\mathrm{k}_{\mathrm{eff}}$ decreases with temperature. In contrast, the phase transition of the moderator leads to a jump in $\mathrm{k}_{\text {eff. }}$ The increase in $\mathrm{k}_{\text {eff }}$ by changing the temperature from $253 \mathrm{~K}$ (with ice as moderator) to $293 \mathrm{~K}$ (with water as moderator) varies from about $2700 \mathrm{pcm}$ (fresh fuel) to $2000 \mathrm{pcm}(45 \mathrm{GWd} / \mathrm{t})$ in the case of the single fuel assembly. In the case of the infinite fuel assembly array, this increase in $\mathrm{k}_{\mathrm{eff}}$ is about $700 \mathrm{pcm}$ and almost independent of the fuel composition.

The results of the different codes are reasonably similar. The differences $\Delta \mathrm{k}_{\text {eff }}\left(=\mathrm{k}_{\text {eff,KENO/OpenMC }}-\mathrm{k}_{\text {eff,MCNP }}\right)$ between the KENO-V.a and MCNP results, and between the OpenMC and MCNP results as well as the statistical uncertainties of $\Delta \mathrm{k}_{\text {eff }}$ are given in Fig. 3. In the case of the single fuel assembly $\Delta \mathrm{k}_{\text {eff }}$ is mostly less than $100 \mathrm{pcm}$ and statistically compatible with zero. Hence, the differences between the corresponding neutron multiplication factors are mostly insignificant. However, the largest discrepancies up to about $200 \mathrm{pcm}$ exist between the KENO-V.a and OpenMC results at $233 \mathrm{~K}$. For the infinite fuel
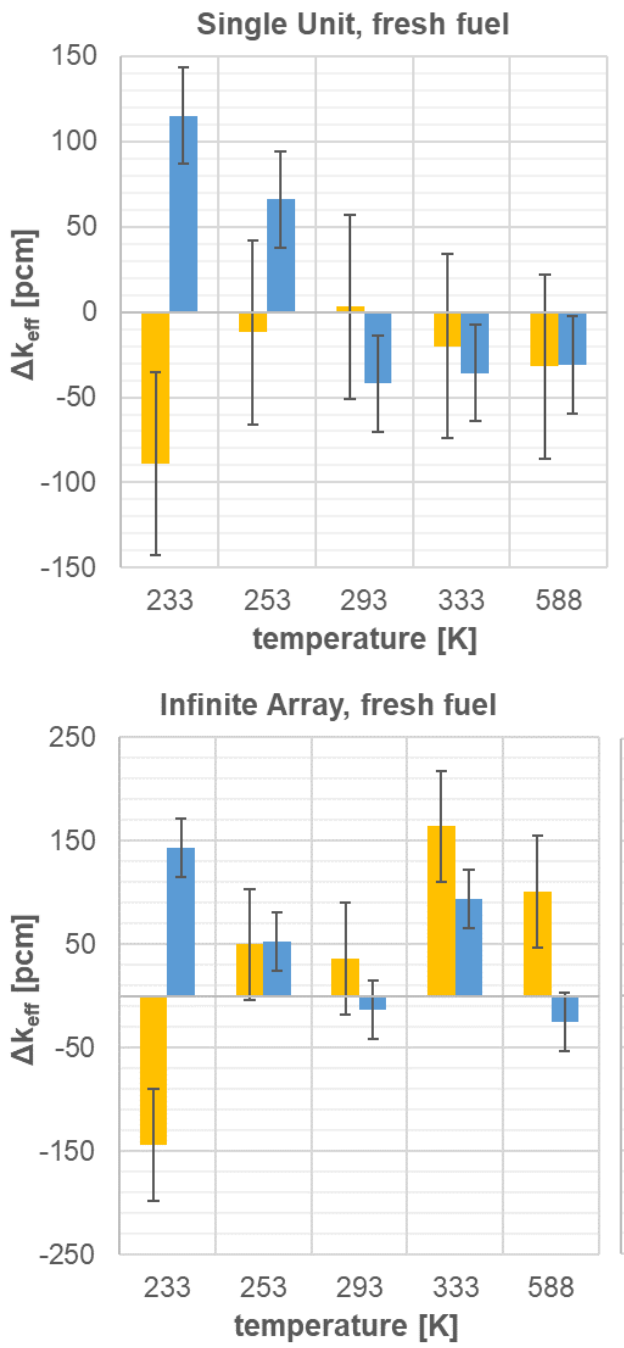

Single Unit, $30 \mathrm{GWd} / \mathrm{t}$

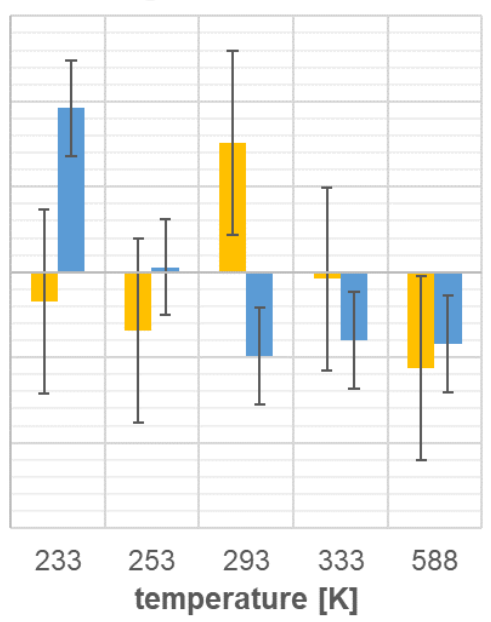

Infinite Array, $30 \mathrm{GWd} / \mathrm{t}$

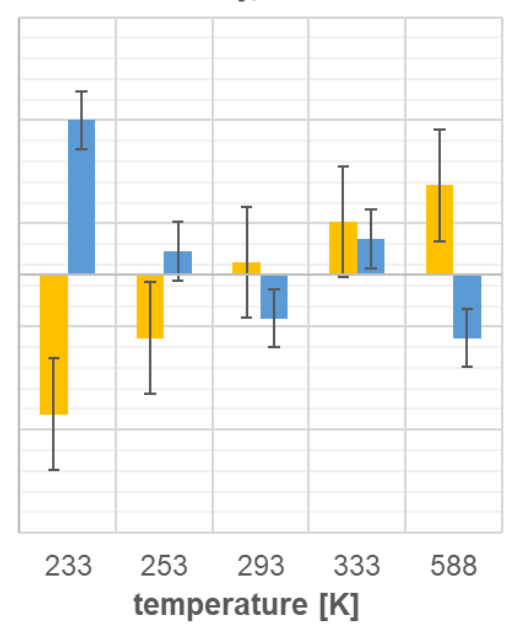

Single Unit, 45 GWd/t

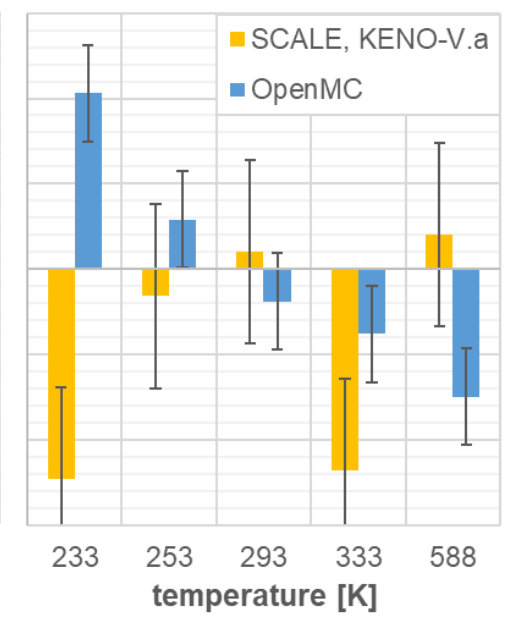

Infinite Array, $45 \mathrm{GWd} / \mathrm{t}$

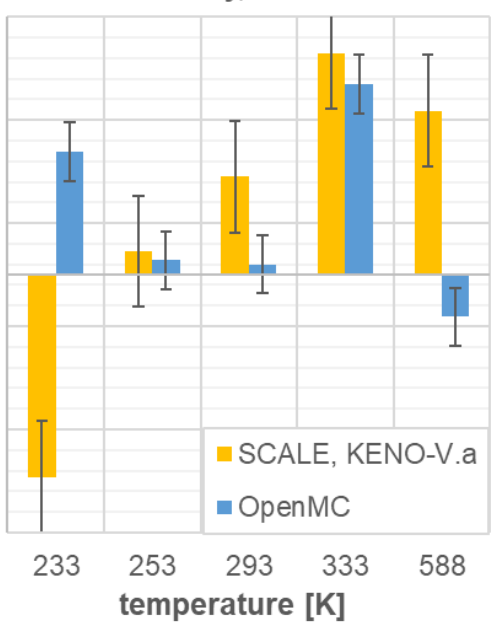

Figure 3. Differences $\Delta \mathrm{k}_{\text {eff }}$ in the neutron multiplication factors between KENO-V.a and MCNP, and between OpenMC and MCNP, respectively. 
assembly array, the results of the different codes show somewhat larger discrepancies. In many cases $\Delta \mathrm{k}_{\text {eff }}$ is still compatible with zero, but it reaches also values up to $200 \mathrm{pcm}$. As before, the largest differences up to $300 \mathrm{pcm}$ exist between the KENO-V.a and OpenMC results at $233 \mathrm{~K}$.

The benchmark results show the combined impact of the temperature-dependent parameters on $k_{\text {eff }}$, but they do not provide enough information to draw any detailed conclusions about the quantitative impact of each single parameter on $\mathrm{k}_{\text {eff. }}$. Therefore, further investigations were performed based on these benchmark specifications.

\subsection{Comparison with other Benchmark Contributions}

In total, more than 30 benchmark contributions were submitted including six contributions from GRS [6]. Several combinations of codes and nuclear data libraries were used to perform the submitted results. In addition to the GRS contributions discussed above, the other three GRS contributions utilized KENO-V.a and the ENDF/B-VII.1 library in different energy group structures, but without thermal scattering data of hydrogen bound in ice. Other benchmark participants also utilized the codes TRIPOLI-4, MORET 5, MVP3, HELIOS 2 or different versions of MONK, as well as the nuclear data libraries JEF-2.2, JEFF3.1.1, JEFF-3.1.2, JEFF-3.3 or JENDL-4.0.

A preliminary evaluation of these contributions has already been published in [6]. It demonstrates, that for each analysed configuration the vast majority of the calculated neutron multiplication factors vary not more than $600 \mathrm{pcm}$. The largest variation appears at the temperature of $588 \mathrm{~K}$, while the variation is considerably lower at all other temperatures. Only two contributions result in systematic larger variations in $\mathrm{k}_{\text {eff }}$, but without any clear explanation so far. However, the GRS contributions are compatible with the vast majority of the contributions, i.e. the calculated neutron multiplication factors are within the mentioned variation in $\mathrm{k}_{\mathrm{eff}}$ of $600 \mathrm{pcm}$.

\section{IMPACT OF EACH TEMPERATURE-DEPENDENT PARAMETER ON $\mathrm{k}_{\mathrm{eff}}$}

Instead of varying reaction cross sections, thermal scattering data and moderator density with temperature simultaneously, the impacts of these parameters on $\mathrm{k}_{\mathrm{eff}}$ were studied separately. For this purpose, only one single parameter was varied with temperature at a time, while all other temperature-dependent parameters were fixed at $293 \mathrm{~K}$.

For this study the benchmark models were used as described above (see chapter 2.1.). Only the temperature range was reduced to $233 \mathrm{~K}-350 \mathrm{~K}$ and $\mathrm{k}_{\mathrm{eff}}$ was calculated for more temperatures to focus the analysis on a temperature region around the moderator phase transition. The temperatures considered to calculate $\mathrm{k}_{\text {eff }}$ were chosen identical to the temperatures of the thermal scattering data sets provided in the ENDF/B-VIII.0 library. In this way, the thermal scattering data of hydrogen bound in ice or water of the ENDF/B-VIII.0 library could be used without any correction or imposing any error on $\mathrm{k}_{\text {eff. }}$ These calculations were performed using MCNP only, since MCNP provides the required functionalities to include reaction cross sections and thermal scattering data separately at different temperatures in a userfriendly way.

The performed parameter variations show that only the variations of the moderator density, of the thermal scattering data of hydrogen and of the reaction cross sections of the fuel have a significant temperaturedependent impact on $k_{\text {eff. }}$ Variations of the reaction cross sections of the moderator as well as of the thermal scattering data of all nuclides excluding hydrogen lead to no significant changes in $\mathrm{k}_{\text {eff }}$ in the analysed temperature range. In Fig. 4 the variations in $\mathrm{k}_{\text {eff }}$ due to the first three mentioned parameters are presented for the fresh fuel cases, with $\Delta \mathrm{k}_{\mathrm{eff}}=\mathrm{k}_{\mathrm{eff}}(\mathrm{T})-\mathrm{k}_{\mathrm{eff}}(293 \mathrm{~K})$. 

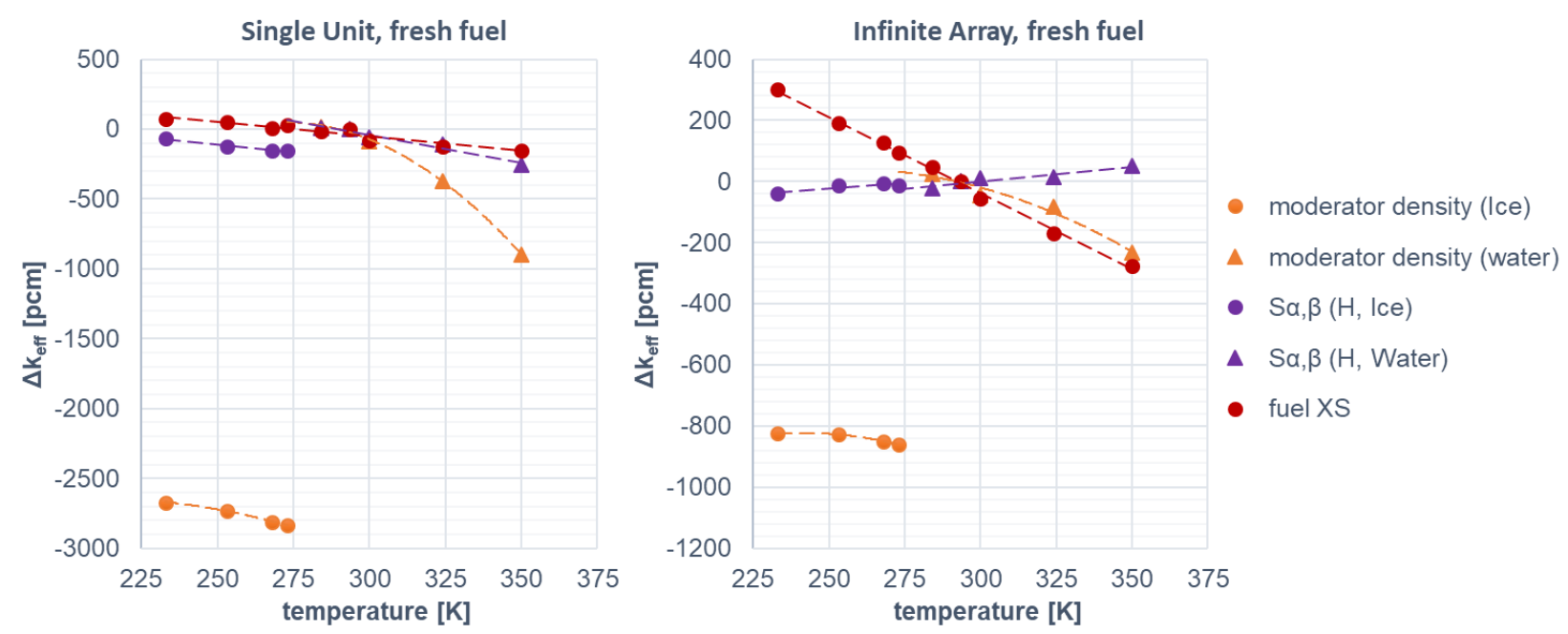

Figure 4. Temperature-dependent impact of the moderator density, the thermal scattering data of hydrogen $\left(S_{\alpha, \beta}\right)$ and the reaction cross sections (XS) of the fuel on $k_{\text {effe }}$

As shown in Fig. 4, the impact of the moderator density and of the reaction cross sections of the fuel on $\mathrm{k}_{\text {eff }}$ show a qualitatively similar behaviour for both analysed fuel assembly configurations. However, their quantitative effects are significantly different. In the case of the infinite fuel assembly array the variations in $k_{\text {eff }}$ due to the temperature-dependence of the reaction cross sections are about twice as large as the variations in the case of the single fuel assembly. In contrast, the temperature-dependence of the moderator density causes considerably smaller variations in $\mathrm{k}_{\text {eff }}$ in the case of the infinite fuel assembly array than in the case of the single fuel assembly. This leads to the fact, that for the infinite fuel assembly array, both parameters have a similar quantitative impact on $\mathrm{k}_{\text {eff. }}$ For the single fuel assembly, the temperature-dependence of moderator density leads to much larger variations in $k_{\text {eff }}$ compared to the variations caused by the reaction cross sections. Also, the jump in $k_{\text {eff }}$ due to the change of the moderator density at the phase transition differs significantly between both configurations. In the case of the single fuel assembly this jump in $\mathrm{k}_{\text {eff }}$ is about $2800 \mathrm{pcm}$ for fresh fuel and decreases to $2400 \mathrm{pcm}$ and $2200 \mathrm{pcm}$ considering the $30 \mathrm{GWd} / \mathrm{t}$ and $45 \mathrm{GWd} / \mathrm{t}$ fuel compositions, respectively. Instead, it varies only between $850 \mathrm{pcm}$ and $1050 \mathrm{pcm}$ in the case of the infinite fuel assembly array.

In contrast to the impact of the moderator density and of the reaction cross sections, the impact of the thermal scattering data of hydrogen on $k_{\text {eff }}$ shows complementary behaviours for both analysed fuel assembly configurations, see Fig. 5. In the case of the single fuel assembly the temperature-dependence of the thermal scattering data of hydrogen causes a decrease in $k_{\text {eff }}$ with temperature, while it results in an increasing $\mathrm{k}_{\text {eff }}$ in the case of the infinite fuel assembly array. Similarly, the change of the thermal scattering data due to the phase transition of the moderator from ice to water leads to an increase in $k_{\text {eff }}$ in the case of the single fuel assembly, but to a decrease in $k_{\text {eff }}$ in the case of the fuel assembly array. Furthermore, the results show a dependency of the jump in $\mathrm{k}_{\text {eff }}$ on the fuel composition. However, also this dependency behaves contrarily for both fuel assembly configurations.

\section{CONCLUSIONS}

The effect of the temperature on the neutron multiplication factor for PWR fuel assemblies was analysed. In the OECD/NEA benchmark the combined effect of the temperature-dependent parameters on $k_{\text {eff }}$ was studied. The benchmark calculations performed by GRS show the expected temperature-dependent 

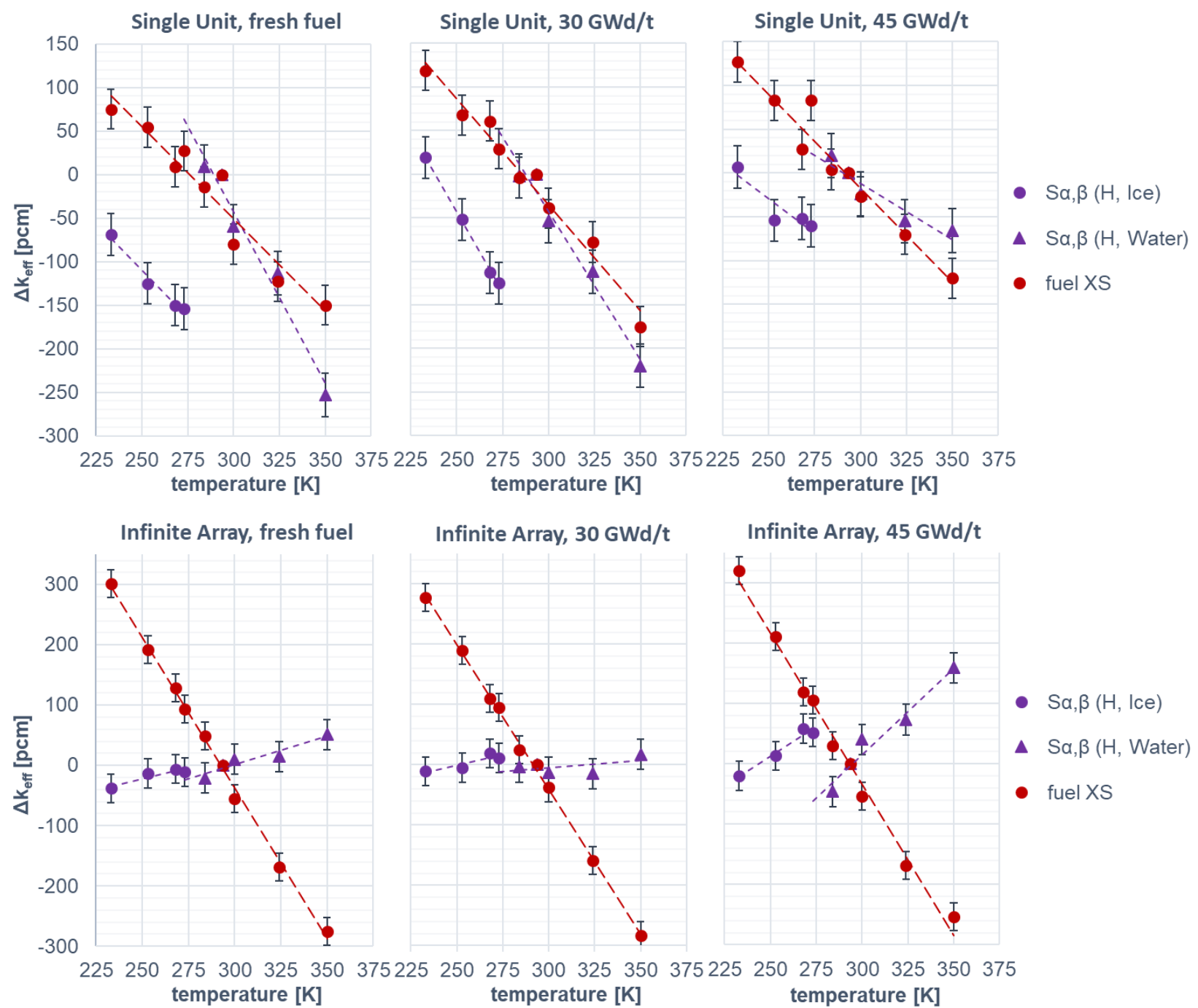

Figure 5. Temperature-dependent impact of the thermal scattering data of hydrogen $\left(S_{a, \beta}\right)$ and the reaction cross sections (XS) of the fuel on $k_{\text {eff }}$ for the different fuel compositions.

behaviour of $\mathrm{k}_{\mathrm{eff}}$, i.e. $\mathrm{k}_{\mathrm{eff}}$ decreases with temperature, and the moderator phase transition leads to a jump in $\mathrm{k}_{\text {eff. }}$ The results calculated with the codes KENO-V.a, OpenMC and MCNP are in good agreement.

An additional study investigated the effects of the temperature-dependent parameters on $\mathrm{k}_{\text {eff }}$ separately. This investigation confirms the well-known effects of the temperature-dependent variations of moderator density and cross sections on $k_{\text {eff. }}$ The temperature-dependence of the neutron multiplication factor is dominated by these two parameters. Especially, the jump in $\mathrm{k}_{\text {eff }}$ at the phase transition of the moderator is mainly due to the change of the moderator density. Furthermore, the investigation demonstrates that the temperature-dependent variations of the scattering data have a relatively small impact on $\mathrm{k}_{\text {eff. }}$ Especially, the change in the scattering data of bound $\mathrm{H}$ at the moderator phase transition leads to a jump in $\mathrm{k}_{\text {eff, }}$ which is much smaller compared to the one caused by the change of the moderator density. 
However, the actual impact of each parameter on $k_{\text {eff }}$ depends strongly on the analysed configuration. In particular, the impact of the scattering data of bound hydrogen on $\mathrm{k}_{\text {eff }}$ shows a complementary behaviour for both analysed fuel assembly configurations.

\section{ACKNOWLEDGMENTS}

This work was funded by the German Federal Ministry for the Environment, Nature Conservation and Nuclear Safety, and supported by the German Federal Office for the Safety of Nuclear Waste Management.

\section{REFERENCES}

1. International Atomic Energy Agency (IAEA), Regulations for the Safe Transport of Radioactive Material. Specific Safety Requirements SSR-6 (1. Rev), International Atomic Energy Agency (IAEA): Wien, Austria (2018).

2. T.C. Ware, D. Hanlon, Research into the Effect of Temperature on the Criticality Safety of Fissile Systems, 203171-AA-0022, ONR352, Rev. 2, Wood Nuclear Limited, Warrington, Cheshire, UK, March 2019.

3. D.A. Brown, et al., "ENDF/B-VIII.0: The $8^{\text {th }}$ Major Release of the Nuclear Reaction Data Library with CIELO-project Cross Sections, New Standards and Thermal Scattering Data", Nuclear Data Sheets, 148, pp. 1-142 (2018).

4. A. Plompen, Announcing JEFF-3.3 release, Technical Report JEFDoc-1864, November 2017.

5. S. Gan, A.R. Wilson, Benchmark Specification: The effect of temperature on the neutron multiplication factor for PWR fuel assemblies, OECD/NEA Working Party on Nuclear Criticality Safety, Subgroup 3, Paris, France, September 2018.

6. S. Gan, A. R. Wilson, "The Effect of Temperature on the Neutron Multiplication Factor for PWR Fuel Assemblies", ICNC 2019 Proceedings, $11^{\text {th }}$ International Conference on Nuclear Criticality Safety (ICNC 2019), Paris, France, September 15-20, 2019 (2019)

7. M. Takano, OECD/NEA Burnup Credit Criticality Benchmark - Result of Phase 1A, JAERI-M 94003, NEA/NSC/DOC(93)22, Japan Atomic Energy Research Institute, Tokai-mura, Naka-gun, Ibaraki-ken, Japan (1994).

8. B.T. Rearden, M.A. Jessee, (Ed.), SCALE Code System, ORNL/TM-2005/39, Version 6.2.2, Oak Ridge National Laboratory (ORNL), Oak Ridge, TN, USA (February 2017). Available from Radiation Safety Information Computational Center as CCC-834.

9. P.K. Romano, N.E. Horelik, B.R. Herman, A.G., Nelson, B. Forget, K. Smith, "OpenMC, A state-ofthe-art Monte Carlo code for research and development," Annals of Nuclear Energy, 82, pp. 90-97 (2015).

10. D.B. Pelowitz, MCNP6 User's Manual, Version 1.0, LA-CP-13-00634, Rev. 0, Los Alamos National Laboratory, Los Alamos, NM, USA (Mai 2013).

11. J.L. Conlin, W. Haeck, D. Neudecker, D.K. Parsons, M.C. White, Release of ENDF/B-VIII.0-Based ACE Data Files, LA-UR-18-24034, Los Alamos National Laboratory, Los Alamos, NM, USA (Mai 2018).

12. D. Wiarda, M.E. Dunn, N.M. Green, M.L. Williams, C. Celik, L.M. Petrie, AMPX-6: A Modular Code System for Processing ENDF/B Evaluations, ORNL/TM-2016/43, Oak Ridge National Laboratory (ORNL), Oak Ridge, TN, USA (April 2016).

13. M. Behler, V. Hannstein, F. Sommer, Temperaturabhängigkeit des Neutronenmultiplikationsfaktors $k_{\text {eff }}$ für DWR-Brennelemente, GRS-543, ISBN 978-3-947685-28-8, Gesellschaft für Anlagen- und Reaktorsicherheit (GRS) gGmbH, Garching, Germany (Juli 2019), in German. 